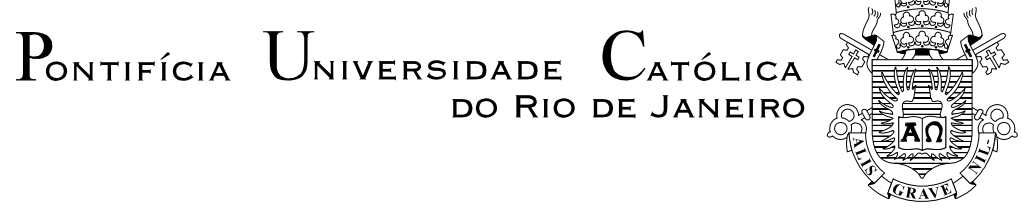

Paulo de Carvalho Junior

Podcasts no ensino de Alemão como Língua Estrangeira um estudo do impacto de uma nova tecnologia

Dissertação apresentada ao Programa de Pósgraduação em Letras da PUC-Rio como requisito parcial para obtenção do grau de Mestre em Letras.

Orientadora: Profa. Bárbara Jane Wilcox Hemais 


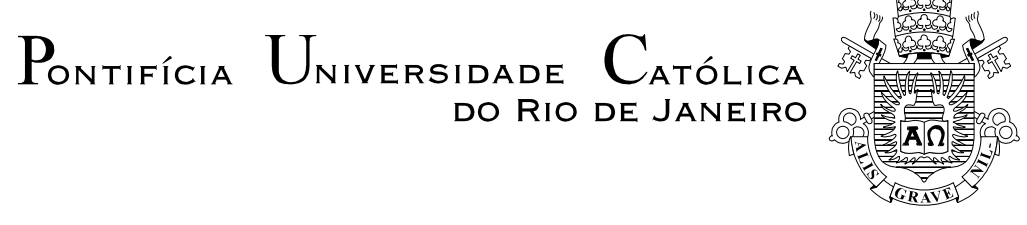

Paulo de Carvalho Junior

\title{
Podcasts no ensino de Alemão como \\ Língua Estrangeira: um estudo do impacto de uma nova tecnologia
}

\begin{abstract}
Dissertação apresentada como requisito parcial para obtenção do grau de Mestre pelo programa de PósGraduação em Letras do Departamento de Letras do Centro de Teologia e Ciências Humanas da PUC-Rio. Aprovada pela Comissão Examinadora abaixo assinada.
\end{abstract}

Profa. Barbara Jane Wilcox Hemais

Orientadora Departamento de Letras - PUC-Rio

Profa. Violeta de San Tiago Dantas Barbosa Quental Departamento de Letras - PUC-Rio

Profa. Magali dos Santos Moura UERJ

Profa. Denise Berruezo Portinari Coordenadora Setorial do Centro de Teologia

e Ciências Humanas - PUC-Rio

Rio de Janeiro, 04 de abril de 2011 
Todos os direitos reservados. É proibida a reprodução total ou parcial do trabalho sem autorização do autor, do orientador e da universidade.

\section{Paulo de Carvalho Junior}

Graduou-se em Letras na UERJ em 2002 (Bacharelado e Licenciatura em Português e Alemão). É professor de alemão junto ao Instituto Goethe do Rio de Janeiro, desde 2002, e à Escola Alemã Corcovado, desde 2004. Atua na área de tecnologia aplicada ao ensino de DaF (Alemão como Língua Estrangeira) participando de congressos e ministrando oficinas em instituições de ensino no Rio de Janeiro e em outros estados.

Ficha Catalográfica

Carvalho Junior, Paulo de

Podcasts no ensino de alemão como língua estrangeira : um estudo do impacto de uma nova tecnologia / Paulo de Carvalho Junior ; orientador: Bárbara Jane Wilcox Hemais. - 2011.

$175 \mathrm{f}$; ; $30 \mathrm{~cm}$

Dissertação (mestrado)- Pontifícia Universidade Católica do Rio de Janeiro, Departamento de Letras, 2011.

Inclui bibliografia

1. Letras - Teses. 2. Alemão como língua

CDD: 400 


\section{Agradecimentos}

À minha orientadora, professora Barbara Hemais, que sempre acreditou em meu trabalho e me mostrou os rumos a seguir.

À PUC-Rio, pelo auxílio concedido, sem o qual este trabalho não poderia ter sido realizado.

Ao Departamento de Letras, pela concessão da bolsa de isenção.

À minha esposa Luciana, pela ajuda inestimável em todos os momentos.

À minha família, pelo apoio constante e incondicional.

Aos meus amigos, por terem relevado minhas ausências.

A todos os professores e funcionários do Departamento de Letras, pela dedicação demonstrada.

À Direção e às Coordenações da Escola Alemã Corcovado, pela compreensão e confiança.

Aos colegas da Escola Alemã Corcovado, em especial Claudia Burkhardt e Olivia Meurer, que tanto contribuíram para este trabalho.

Aos técnicos em informática da Escola Alemã Corcovado, Ewerton Vieira, Ricardo Marques e Rogério Pereira, por todo o suporte.

Aos colegas do Instituto Goethe, em especial Fernando Gil e Ebal Bolaccio, que tanto me incentivaram a ingressar no mestrado.

Às professoras Magali Moura, Violeta Quental e Lúcia Pacheco, que gentilmente aceitaram participar da Comissão Examinadora.

Aos meus colegas da PUC-Rio, sobretudo Fellipe Silva, pela amizade e bom humor para lidar com os momentos mais difíceis do trabalho. 


\section{Resumo}

Carvalho Junior, Paulo de; Hemais, Bárbara Jane Wilcox. Podcasts no ensino de Alemão como Língua Estrangeira: um estudo do impacto de uma nova tecnologia. Rio de Janeiro, 2011, 175p. Dissertação de Mestrado - Departamento de Letras, Pontifícia Universidade Católica do Rio de Janeiro.

Este trabalho investiga o emprego de podcasts de programas de rádio e televisão da Alemanha nas aulas de Alemão como Língua Estrangeira em níveis B2 e C1 do Quadro Europeu Comum de Referência para Línguas no Ensino Médio. Através desta tecnologia, é possível ter acesso rápido e gratuito a materiais autênticos de áudio ou vídeo, de forma que professores passam a ter um leque mais amplo de recursos para suas aulas e alunos passam a ter contato com a língua produzida com outros fins, que não didáticos. Considerando as proposições apresentadas nos Parâmetros Curriculares Nacionais para o Ensino Médio, os níveis de referência descritos no Quadro Europeu Comum de Referência para Línguas e os objetivos traçados no Rahmenplan "Deutsch als Fremdsprache" für das Auslandsschulwesen (Quadro de "Alemão como Língua Estrangeira" para as escolas no exterior), o trabalho discute o potencial e as limitações do uso desta tecnologia como ferramenta no processo de ensino e aprendizagem de Alemão como Língua Estrangeira no contexto escolar. A partir dos pressupostos da Teoria da Atividade, o trabalho procura investigar de que forma a implementação dos podcasts afeta o sistema da atividade da aula de Alemão como Língua Estrangeira nas perspectivas de professores e alunos em uma escola bilíngue da cidade do Rio de Janeiro.

\section{Palavras-chave}

Alemão como Língua Estrangeira; Podcast; Teoria da Atividade; Ensino de Língua Estrangeira; Parâmetros Curriculares Nacionais para o Ensino Médio; Quadro Europeu Comum de Referência para Línguas. 


\section{Abstract}

Carvalho Junior, Paulo de; Hemais, Bárbara Jane Wilcox. Podcasts in the teaching of German as a Foreign Language: a study of the impact of a new technology. Rio de Janeiro, 2011, 175p. M.A. Dissertation Departamento de Letras, Pontifícia Universidade Católica do Rio de Janeiro.

This dissertation investigates the use of podcasts in high school classes of German as a Foreign Language (GFL), in levels B2 and C1 of the Common European Framework of References for Languages. This technology provides for quick and free access to authentic audio or video materials taken from German radio and TV programs, so that teachers have a wider range of resources for their classes and students have contact with the language which was produced for purposes other than pedagogical ones. Considering the proposals in the Parâmetros Curriculares Nacionais para o Ensino Médio (National High School Curricular Parameters), the levels of reference of the Common European Framework of References for Languages, and the goals set in the Rahmenplan "Deutsch als Fremdsprache" für das Auslandsschulwesen (Framework "German as a Foreign Language" for schools abroad), this study discusses the potential and the limitations of the use of this technology as a tool for teaching and learning GFL in a bilingual school. Based on the principles of Activity Theory, this work aims to investigate how the implementation of podcasts affects the activity system of GFL classes from the teachers' and students' perspectives in a bilingual school in Rio de Janeiro.

\section{Keywords}

German as a Foreign Language; Podcast; Activity Theory; Foreign Language Teaching; National High School Curricular Parameters; Common European Framework of References for Languages. 


\section{Sumário}

1 Introdução 14

1.1 Objetivos 15

1.2 Constituição da Pesquisa 16

$\begin{array}{ll}1.3 \text { Estrutura do Trabalho } & 17\end{array}$

2 Teoria da Atividade $\quad 18$

3 O ensino de L2 30

4 Tecnologia no Ensino 43

5 Tecnologia e Mídia 52

5.1 Parâmetros Curriculares Nacionais (Ensino Médio) 52

5.2 O Quadro Comum Europeu de Referência para Línguas e o Quadro do "Alemão como Língua Estrangeira" para as Escolas no Exterior

6 Podcasts 69

7 Metodologia 81

7.1 Implementação dos podcasts na Escola 81

7.1.1 Algumas atividades propostas 86

7.1.1.1 Video online selecionado pelo professor. Global Ideas: Der Kampf gegen den Klimawandel

7.1.1.2 Podcasts de vídeo selecionados pelo professor. Quadriga: Der internationale Talk

7.1.1.3 Podcast de vídeo selecionado pelo professor. neuneinhalb

7.1.1.4 Podcast de áudio selecionado pelo professor. Wissenswert 
7.2.1 Aplicação da metodologia 102

7.2.1.1 Perspectiva do professor 102

$\begin{array}{ll}\text { 7.2.1.2 Perspectiva do aluno } & 104\end{array}$

8 Análise de Resultados $\quad 107$

8.1 Sistemas produtores de ferramentas da atividade central Ensino de ALE

8.2 Contradições resultantes do acréscimo dos podcasts ao leque de ferramentas disponíveis ao professor e ao aluno

9 Considerações Finais

Referências Bibliográficas

123

Anexo 1 Modelo do Questionário dos Alunos e Tabulação dos Dados

134

Tabulação dos Questionários com as Respostas dos Alunos

Anexo 2 Questionários dos Professores

152

Anexo 3 Manual de Instalação do iTunes e de Assinatura de Podcasts desenvolvido e fornecido para os Alunos 


\section{Lista de Tabelas}

Tabela 1. Correlação entre o RDAF e o QECR. 60

Tabela 2. Correlação entre o RDAF e o QECR. 62

Tabela 3. Correlação entre o RDAF e o QECR. 64

Tabela 4. Correlação entre o RDAF e o QECR. 66

Tabela 5. Podcasts de rádio. $\quad 84$

Tabela 6. Podcasts de televisão. $\quad 85$

Tabela 7. Notação da atividade. 101

Tabela 8. Notação da atividade dos professores de ALE. 103

Tabela 9. Notação da atividade dos alunos. 105 


\section{Lista de Figuras}

Figura 1. Modelo de Vygotsky da ação mediada e sua reformulação usual. $\quad 19$

Figura 2. Estrutura hierárquica da atividade segundo Leontiev. 21

Figura 3. Estrutura de um sistema de atividade humana. 23

Figura 4. Dois sistemas de atividade em interação como modelo mínimo para a terceira geração da TA.

Figura 5. Quatro níveis de contradições dentro do sistema de atividade humana.

Figura 6. Fragmento de exercícios.

Figura 7. Representação de aula. 32

Figura 8. Diálogo apresentado em aula. 33

Figura 9. Transcrição de aula.

Figura 10. Representação de aula. 34

Figura 11. Fragmentos de aula. 35

Figura 12. Representação de aula. 36

Figura 13. Excerto de livro didático. 40

Figura 14. Excerto de livro didático. 41

Figura 15. Modelo da teoria cognitiva de aprendizagem multimídia de Richard Mayer. $\quad 47$

Figura 16. Níveis de proficiência.

Figura 17. Visualização de podcasts assinados no iTunes. $\quad 69$

Figura 18. Captura de tela de exemplo de Áudio on demand do site da Rádio Band News FM.

Figura 19. Captura de tela de exemplo de Áudio on demand do site da Rádio CBN. 
Figura 20. Captura de tela de exemplo de podcasts disponíveis do site da Rádio CBN.

Figura 21. Taxonomia dos usos de podcast para o aprendizado de línguas.

Figura 22. Fragmento da transcrição do Video-Thema exibido em 12/01/2011, Naturschutzgebiete in Gefahr.

Figura 23. Fragmento das tarefas sugeridas pela emissora DW-TV para o Video-Thema exibido em 12/01/2011, Naturschutzgebiete in Gefahr.

Figura 24. Captura de tela de vídeo on demand disponível no site da Deutsche Welle.

Figura 25. Captura de tela da assinatura de feeds na iTunes Store.

Figura 26. Captura de tela da descrição do episódio BurkaVerbot - wieviel Schleier verträgt eine Gesellschaft? Disponível no iTunes.

Figura 27. Fragmento de tarefa desenvolvida para o episódio Burka-Verbot - wieviel Schleier verträgt eine Gesellschaft?

Figura 28. Fragmento de tarefa desenvolvida para o episódio Burka-Verbot - wieviel Schleier verträgt eine Gesellschaft?

Figura 29. Fragmento de tarefa desenvolvida para o episódio Burka-Verbot - wieviel Schleier verträgt eine Gesellschaft?

Figura 30. Captura de tela da descrição do episódio Was glaubst du? - Buddhismus disponível no iTunes.

Figura 31. Captura de tela do episódio Was glaubst du? Buddhismus.

Figura 32. Fragmento de tarefa desenvolvida para o episódio Die Ursprünge der Popmusik im Gospel.

Figura 33. Captura de tela da página onde é possível baixar o script do programa Die Ursprünge der Popmusik im Gospel. Detalhe para o link de download.

Figura 34. Fragmento do script do programa Die Ursprünge der Popmusik im Gospel.

Figura 35. Fragmento de tarefa desenvolvida a partir do script. 
Figura 36. O ensino tradicional e o ir à escola como sistemas de atividades interconectados.

Figura 37. Sistema de organização da atividade. 101

Figura 38. Sistema da atividade de ensino de ALE. 102

Figura 39. Sistema da atividade de aprendizagem de ALE. 104

Figura 40. Sistema da atividade de produção de material didático: tarefas de áudio e vídeo de ALE. 108

Figura 41. Sistema da atividade de produção de material didático: tarefas de áudio e vídeo de ALE baseadas em podcast.

Figura 42. Contradição secundária entre sujeito e divisão do trabalho.

Figura 43. Contradição secundária entre sujeito e ferramenta. 112

Figura 44. Contradição terciária entre o objeto da forma dominante e o objeto de uma forma culturalmente mais avançada da atividade central.

Figura 45. Contradição quaternária entre o objeto da atividade central e o objeto de uma atividade periférica. 


\title{
Lista de Abreviaturas e Siglas
}

\author{
ALE - Alemão como Língua Estrangeira \\ DaF - Deutsch als Fremdsprache (Alemão como Língua Estrangeira) \\ DFU - Deutschsprachiger Fachunterricht (Disciplinas de Conteúdo em \\ Alemão) \\ DSD - Deutsches Sprachdiplom (Diploma de Língua Alemã) \\ EAC - Escola Alemã Corcovado \\ EM - Ensino Médio \\ GL - Gesellschaftslehre (Estudos Sociais em Língua Alemã) \\ L1 - Lígua Materna \\ L2 - Língua Estrangeira ou Segunda Língua \\ PCN - Parâmetros Curriculares Nacionais \\ PCNEM - Parâmetros Curriculares Nacionais para o Ensino Médio \\ PDF - Portable Document Format \\ QECR - Quadro Europeu Comum de Referência para Línguas \\ RDFA - Rahmenplan 'Deutsch als Fremdsprache' für das \\ Auslandsschulwesen (Quadro do "Alemão como Língua \\ Estrangeiras" para as Escolas no Exterior) \\ RSS - Really Simple Syndication \\ TA - Teoria da Atividade \\ TIC - Tecnologias de Informação e Comunicação
}

